\title{
АНАЛИЗ УСТОЙЧИВОСТИ МЕЖДУКАМЕРНОГО ЦЕЛИКА ПРИ ЗАЛПОВОМ ПРОРЫВЕ ВОДЫ ЧЕРЕЗ ГИДРОИЗОЛИРУЮЩУЮ ПЕРЕМЫЧКУ
}

\author{
Е.А. Губанова \\ Горный институт УрО РАН, г. Пермь.
}

\begin{abstract}
Аннотация: Выполнены оценочные расчеты аварийного поступления воды в горные выработки рудника СКРУ-1 вследствие возникновения прорана в окрестности гидроизолирующей перемычки в сбойке между рудниками СКРУ-1 и СКРУ-2. Методами математического моделирования проведена оценка устойчивости междукамерного целика при залповом воздействии на него струи воды. Численное моделирование выполнено в трехмерной постановке в рамках прочностного статического анализа механики твердого деформируемого тела. С использованием критерия Кулона-Мора проведен анализ потенциальной возможности формирования микротрещин в горной породе. Представлены результаты анализа характера разрушения междукамерного целика в терминах коэффициента безопасности (запаса прочности). Приведена сравнительная оценка устойчивости междукамерного целика в отсутствии силового воздействия рассола.

Ключевые слова: математическое моделирование; междукамерный целик; проран; узловая сила; коэффициент безопасности.
\end{abstract}

\section{Введение}

В ноябре 2014 года на руднике СКРУ-2 отмечено поступление ненасыщенных рассолов в выработанное пространство. Шахтное поле рудника СКРУ-2 граничит с полем рудника СКРУ-1. Шахтные поля разделены целиком, через который по пласту АБ пройдена одиночная выработка (сбойка). В сбойке с целью недопущения прорыва рассолов в горные выработки рудника СКРУ-1 возведена гидроизолирующая перемычка. В статье рассмотрены потенциально возможные последствия внезапного прорыва воды через перемычку, связанные с опасностью разрушения целиков в выработанном пространстве рудника СКРУ-1. В расчетах принималось, что при полном затоплении рудника СКРУ-2 давление рассолов в районе гидроизолирующей перемычки будет составлять порядка 25 атмосфер.

\section{Основные методические положения расчетов}

Математическое моделирование выполнялось в трехмерной постановке в рамках прочностного статического анализа механики твердого деформируемого тела. Связь между напряжениями и деформациями определялась законом Гука:

$$
\{\sigma\}=[D] \cdot\{\varepsilon\}
$$

где $[D]$ - матрица упругости изотропного материала [1]. Относительные деформации в пределах конечного элемента вычислялись согласно соотношению:

$$
\{\varepsilon\}=[B] \cdot\{u\}
$$

где $[B]$ - матрица функций формы, $\{u\}$ - вектор перемещений.

Разрешающее уравнение статического анализа записывается в виде:

$$
[K] \cdot\{u\}=\{F\}
$$

где $[K]$ - глобальная матрица жесткости. В качестве компонентов глобального вектора сил $\{F\}$ могут выступать сосредоточенные силы, давление, силы инерции. Глобальная 
матрица жесткости и вектор узловых сил строились путем сумммирования по всем объемным конечным элементам. Следует отметить, что матрица жесткости является симметричной и имеет ленточную структуру. Из решения данной системы алгебраических уравнений (3), согласно соотношений (1), (2), определялись все компоненты тензора деформаций и напряжений.

Статический анализ включал оценку разрушения междукамерного целика, основанную на использовании критерия пластичности, записанном в виде классической формы закона Кулона-Мора [2]

$$
\tau_{\max }=\tau_{n p}=C+\sigma_{n} \operatorname{tg} \varphi
$$

с коэффициентом сцепления $C$ и коэффициентом внутреннего трения $\operatorname{tg} \varphi$. Касательное $\left(\tau_{\max }\right)$ и нормальное $\left(\sigma_{n}\right)$ напряжения определяются на площадках, где отношение $\tau_{\max } / \tau_{\text {пр }}$ достигает максимального значения.

Напряжения $\tau_{\max }$ и $\sigma_{\mathrm{n}}$ в выражении (4) вычисляются через значения главных напряжений:

$$
\begin{gathered}
\tau_{\max }=\left(\sigma_{1}-\sigma_{3}\right) / 2 ; \\
\sigma_{\mathrm{n}}=\left(\sigma_{1}+\sigma_{3}\right) / 2 .
\end{gathered}
$$

В расчетах модуль деформации целика принимался равным $E=1$ Па, коэффициент Пуассона - $v=0,3$. Пределы прочности на растяжение $\left(\sigma_{\text {раст }}\right)$ и сжатие $\left(\sigma_{c ж}\right)$ для сильвинитовой породы составляли соответственно 1 МПа и 19MПа. При количественной оценке возможности разрушения междукамерного целика его прочностные характеристики корректировались с учетом коэффициента длительной прочности.

Численная реализация математического моделирования выполнялась методом конечных элементов [1] с дискретизацией рассматриваемой области на объемные элементы. Для оценки эффективности различных расчетных сеток с применением объемных элементов в виде тетраэдров и гексаэдров были проведены тестовые расчеты. Установлено, что различные сетки практически не оказывают влияния на полученные результаты. В связи с чем для дальнейшего исследования использовалась расчетная сетка с объемными элементами в виде тетраэдров. Общее число конечных элементов при решении данной задачи составило порядка 1000000.

\section{Постановка задачи}

Расчетная схема математического моделирования представлена на рис. 1. В расчетах рассматривался изотропный породный массив, вмещающий систему очистных камер с параметрами: ширина камеры 14; длина - 200 м; высота - 3,5 м. Ширина междукамерных целиков составляет 13 м, ширина штрека между камерами - 10 м. Глубина отработки $(H)$ соответствовала 250 м. Геометрическая модель массива представляет собой параллелепипед, очистные камеры в котором смоделированы в виде системы прямоугольных вырезов. Ось $Z$ прямоугольной системы координат направлена параллельно линии длины очистных камер, ось $\mathrm{X}$ - в перпендикулярном направлении, ось Y соответствует глубине горных работ, начало отсчета системы координат показано на рисунке. Граничные условия определялись следующим образом: горизонтальные смещения на боковых гранях параллелепипеда, лежащих параллельно координатной плоскости zоy (x=0 м, x=162 м) и вертикальные на нижней грани в плоскости вох ( $=0$ м) при- 
нимались равными нулю. На торцевых гранях, параллельных координатной плоскости $\boldsymbol{x} \boldsymbol{y}(\mathrm{z}=0$ м, z=205 м) задавались нулевые смещения по оси z. Верхняя поверхность, параллельная плоскости zоx ( $=103,5$ м), находилась под действием приложенного веса вышележащих пород. Учет собственного веса пород проводился посредством задания массовых сил интенсивностью $\gamma_{i}\left(\gamma_{i}-\right.$ удельный вес $i$-го элемента).

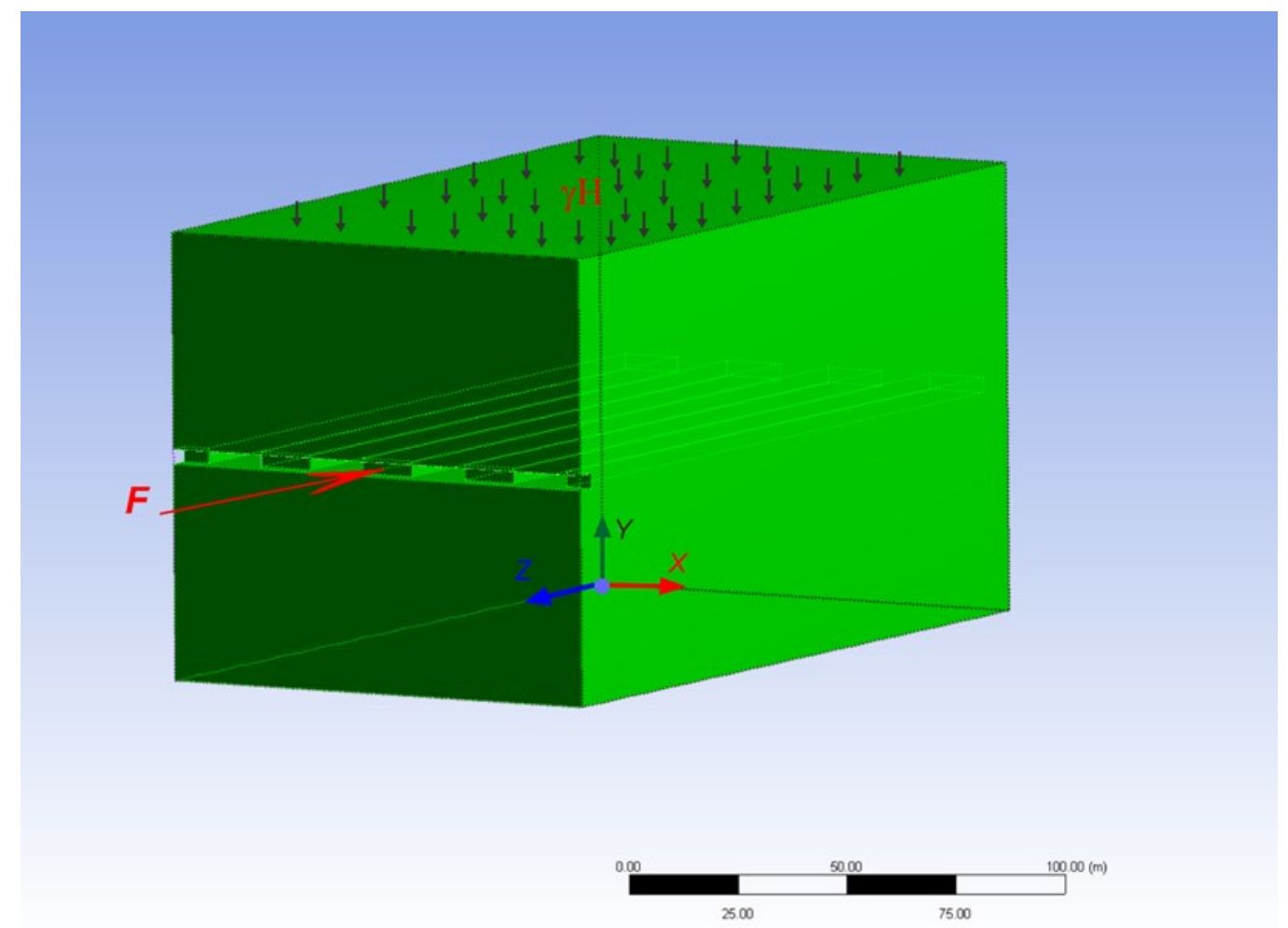

Рис. 1. Расчетная схема

При образовании прорана возможен вариант, когда струя рассола под давлением 25 атмосфер воздействует непосредственно на междукамерный целик. В расчетах давление струи рассола на целик заменялось действием узлового усилия $F$ (рис. 1). Предполагалось, что струя воды ударяет по центру целика (рис. 1). Моделирование характера разрушения междукамерного целика производилось при образовании в окрестности гидроизолирующей перемычки прорана квадратного сечения с ребром: 0,2 м; 0,4 м и 0,8 м. Принималось, что давление струи соответствует отношению силы к площади ее действия. Тогда для каждого из трех вариантов прорана при одном и том же давлении струи в 25 атмосфер значение силы будет соответствовать следующим величинам:

1) проран с ребрами 0,2 м (площадь $0,04 \mathcal{M}^{2}$ ) - прилагаемое усилие $F=101325 \mathrm{H}$;

2) проран с ребрами 0,4 м (площадь $\left.0,16 \mathcal{M}^{2}\right)-F=405300 \mathrm{H}$;

3) проран с ребрами 0,8 м (площадь $0,64 \mathcal{M}^{2}$ ) $-F=1621200 \mathrm{H}$.

Анализ характера разрушения междукамерного целика производился в терминах коэффициента безопасности (запаса прочности) [3] согласно выражению:

$$
R=\frac{\tau_{n p}}{\tau_{\max }},
$$

где $\tau_{n p}$ определяется выражением (4), а $\tau_{\text {max }}$ - соответственно (5). Участки целика, в пределах которых $R \leq 1$, считаются подверженными разрушению. 


\section{Анализ устойчивости междукамерного целика при залповом прорыве воды}

Для сравнения оценивалось состояние междукамерного целика в его естественном режиме деформирования, то есть в отсутствии силового воздействия рассола. Результаты выполненного численного моделирования представлены на рис. 2. Здесь показано горизонтальное сечение, расположенное в срединной плоскости междукамерного целика. Как видно, опасные зоны, связанные с нарушением устойчивости междукамерного целика, отмечаются в его краевых частях на границе со штреком и вдоль границ с очистными камерами. Данные зоны выделены красным цветом.
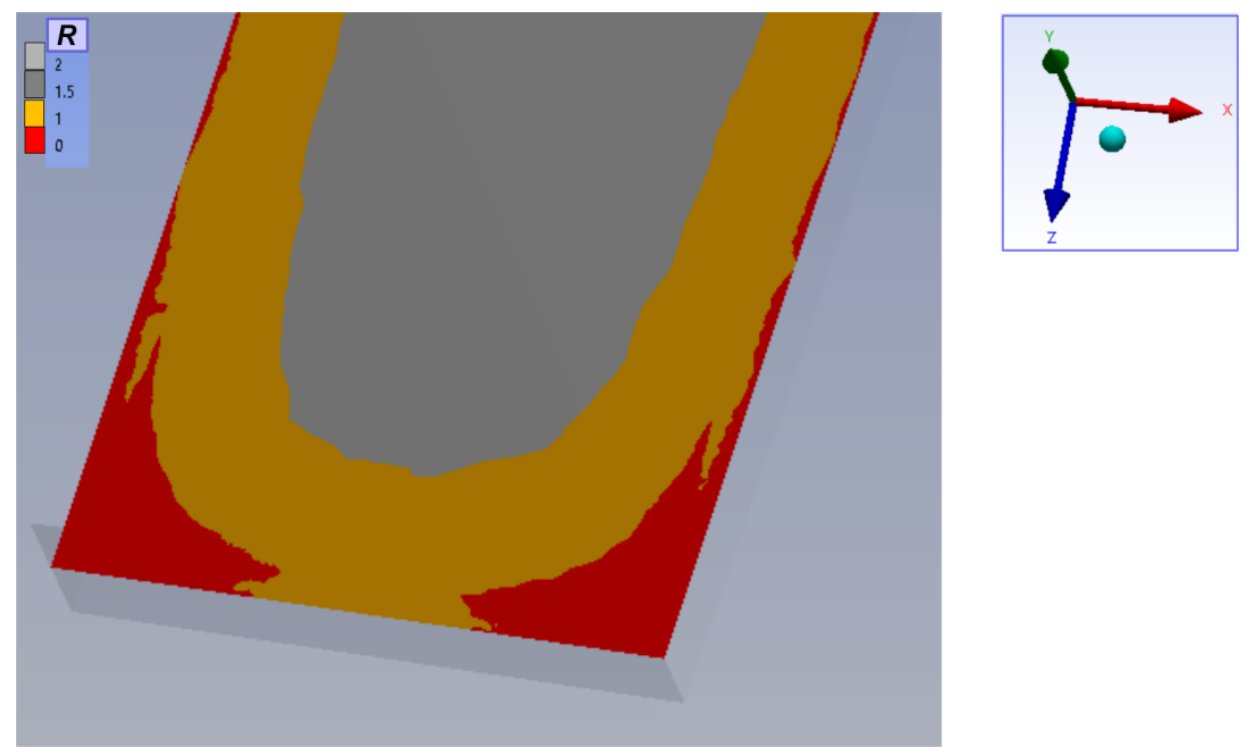

Рис. 2. Распределение коэффициента безопасности в междукамерном целике в отсутствии воздействия рассолов

По мере удаления от границ выработки к центру целика запас прочности, определяемый критериальным параметром $R$ (6), возрастает (рис. 2).

При образовании в окрестности гидроизолирующей перемычки прорана квадратного сечения с ребром 0,2 м; 0,4 м и 0,8 м (соответственно, рис. 3, а, б, в) распределение критериального параметра $R$ вблизи границы целика со штреком изменяется незначительно.

Как видно, здесь образуются локальные зоны разрушения междукамерного целика (рис. 3). С увеличением размеров ребер прорана до 0,8 м происходит некоторый рост процесса разрушения как вглубь междукамерного целика, так и на границе целика со штреком (рис. 3, а, б, в). Рост разрушения происходит по направлению струи рассола вдоль оси z (рис. 3, в). Визуализация распределения критериального параметра $R$ показывает, что вода проникает вглубь целика на расстояние порядка 0,5 м (рис. 3).

Таким образом, по результатам математического моделирования установлено, что увеличение размеров ребер сечения прорана от 0,2 м до 0,8 м не приводит к каким-либо значительным изменениям критериального параметра $R$ и росту микротрещин в горной породе, и, как следствие, снижению прочности междукамерного целика.

Выполненная оценка опасности статического разрушения междукамерных целиков под воздействием высоконапорного давления рассолов показала, что процесс разрушения локализован и не ведет к мгновенной потери устойчивости целика. Следует отметить, что полученные результаты анализа являются приближенными и не учитывают все особенности этого сложного процесса (динамику силового воздействия, эффекты размыва, наличие зон трещиноватости $[4,5]$ и др.). Для получения более достоверных оценок целесообразно выполнить комплекс шахтных исследований по воздействию напорного давления рассолов (воды) на междукамерные целики. 


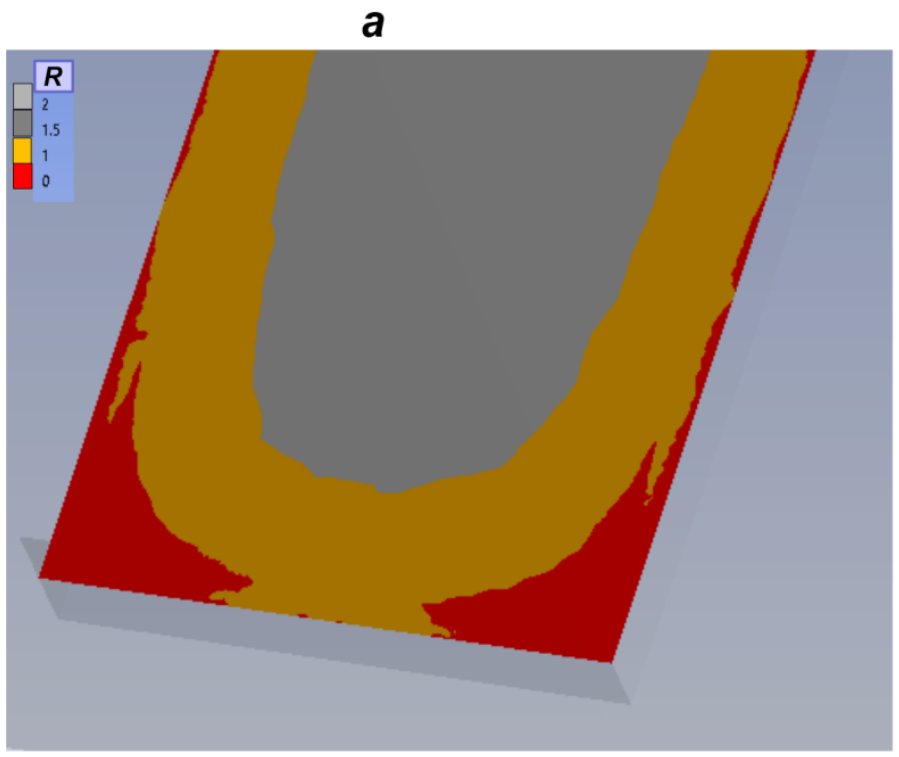

$\sigma$
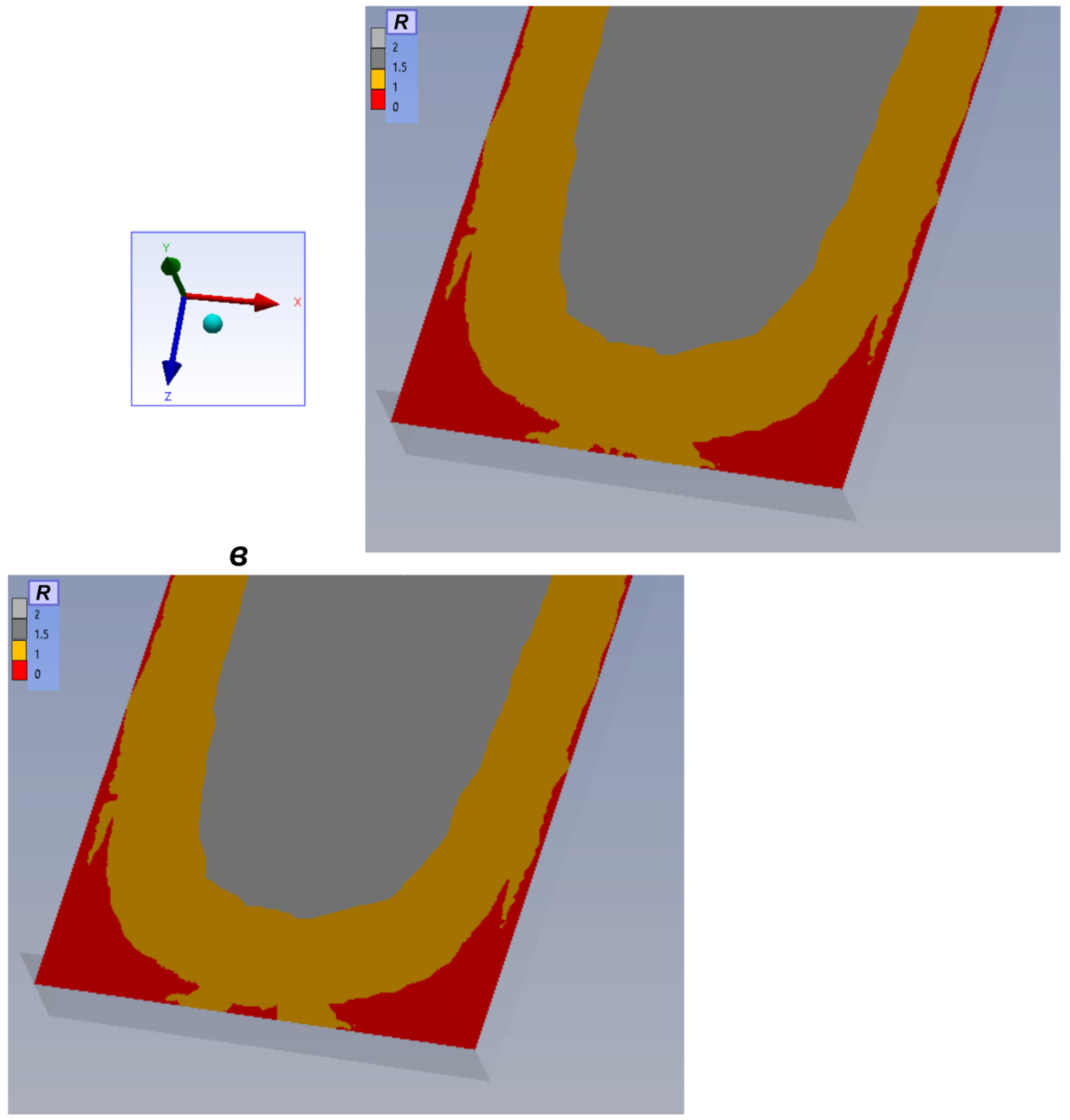

Рис. 3. Распределение критериального параметра $R$ при наличии прорана с ребром 0,2 м (a); 0,4 м (б); 0,8 м (в)

Работа выполнена при финансовой поддержке гранта РНФ № 19-77-30008 


\title{
БИБЛИОГРАФИЧЕСКИЙ СПИСОК
}

1. Зенкевич О. Метод конечных элементов в технике. - М.: Мир, 1975. - 541 с.: ил.

2. Кузнецов Г.Н. Механические свойства горных пород. - М.: Углетехиздат. - 1947. - 180 с.

3. Барях А.А., Самоделкина Н.А. К расчету устойчивости целиков при камерной системе разработки // Физико-технические проблемы разработки полезных ископаемых. - 2007. - № 1. - С. 11-20.

4. Барях А.А, Маловичко А.А., Шумихина А.Ю. Формирование зон техногенной нарушенности над выработанным пространством калийных рудников // Физико-технические проблемы разработки полезных ископаемых. - 1996. - № 2. - С. 36-47.

5. Барях А.А., Федосеев А.К. Геомеханический прогноз распределения зон трещиноватости в соляной толще Верхнекамского месторождения калийных солей // Физико-технические проблемы разработки полезных ископаемых. - 2007. - № 5. - С. 11-21.

УДК 622.831

DOI:10.7242/echo.2020.3.8

\section{ЭКСПЕРИМЕНТАЛЬНЫЕ ИССЛЕДОВАНИЯ ВЛИЯНИЯ ДЛИНЫ ПРЯМОУГОЛЬНЫХ ОБРАЗЦОВ СИЛЬВИНИТА НА КОЭФФИЦИЕНТ ФОРМЫ}

\author{
И.Л. Паньков, А.А. Ударцев \\ Горный институт УрО РАН, г. Пермь
}

\begin{abstract}
Аннотация: Для оценки влияния протяженности поддерживающих целиков на их устойчивость проведены исследования на сжатие прямоугольных образцов сильвинита, имеющих размеры: ширина -35 мм, высота - 35 и 70 мм, длина - 35, 70, 140 и 210 мм. По результатам экспериментов получены прочностные показатели, используемые для построения экспериментальных зависимостей влияния длины образца на коэффициент формы.

Ключевые слова: протяженность поддерживающих целиков, несущая способность, коэффициент формы, образцы сильвинита различной длины.
\end{abstract}

Разработка месторождений полезных ископаемых подземным способом невозможна без поддержания налегающей толщи пород с помощью оставляемых целиков различного назначения. Например, на рудниках Верхнекамского месторождения калийных солей (ВКМКС) применяется камерная система разработки с оставлением прямоугольных ленточных поддерживающих целиков, обеспечивающих сохранность сплошности водозащитной толщи, предохраняющей продуктивные отрабатываемые пласты от поступления пресных вод из вышележащих водоносных горизонтов. Для оценки несущей способности целиков используют коэффициент формы, который определяется на образцах с различным отношением высоты $(h)$ к ширине $(a)$ в лабораторных условиях. Достаточно подробный обзор существующих зависимостей коэффициента формы, а также их классификация изложена в работе [1]. Используемые для определения несущей способности соляных пород расчетные зависимости коэффициента формы приведены в работах $[2,3]$. Согласно предложенной классификации, существующие зависимости, традиционно используемые при определении несущей способности поддерживающих целиков, подразделяют на прямые, гиперболические и логарифмические [1]. По результатам испытаний соляных пород, проведенных в ГИ УрО РАН, предложено коэффициент формы записывать в виде экспоненциальной зависимости $[4,5]$. Несмотря на значительное количество предложенных уравнений, известные зависимости определения коэффициента формы не включают в свое математическое выражение влияние протяженности целиков, что может приводить к существенным погрешностям оценки несущей способности поддерживающих элементов подземных конструкций, влияющей как на безопасность ведения горных работ, так и на коэффициент извлечения полезных ископаемых. 